University of Wollongong

Research Online

Faculty of Engineering and Information

Faculty of Engineering and Information

Sciences - Papers: Part A

Sciences

$1-1-2014$

Comparative study of vehicle tyre-road friction coefficient estimation with a novel cost-effective method

\author{
Boyuan Li \\ University of Wollongong, bl995@uowmail.edu.au \\ Haiping Du \\ University of Wollongong, hdu@uow.edu.au \\ Weihua Li \\ University of Wollongong, weihuali@uow.edu.au
}

Follow this and additional works at: https://ro.uow.edu.au/eispapers

Part of the Engineering Commons, and the Science and Technology Studies Commons

Research Online is the open access institutional repository for the University of Wollongong. For further information contact the UOW Library: research-pubs@uow.edu.au 


\title{
Comparative study of vehicle tyre-road friction coefficient estimation with a novel cost-effective method
}

\begin{abstract}
This paper qualitatively and quantitatively reviews and compares three typical tyre-road friction coefficient estimation methods, which are the slip slope method, individual tyre force estimation method and extended Kalman filter method, and then presents a new cost-effective tyre-road friction coefficient estimation method. Based on the qualitative analysis and the numerical comparisons, it is found that all of the three typical methods can successfully estimate the tyre force and friction coefficient in most of the test conditions, but the estimation performance is compromised for some of the methods during different simulation scenarios. In addition, all of these three methods need global positioning system (GPS) to measure the absolute velocity of a vehicle. To overcome the above-mentioned problem, a novel cost-effective estimation method is proposed in this paper. This method requires only the inputs of wheel angular velocity, traction/brake torque and longitudinal acceleration, which are all easy to be measured using available sensors installed in passenger vehicles. By using this method, the vehicle absolute velocity and slip ratio can be estimated by an improved nonlinear observer without using GPS, and the friction force and tyre-road friction coefficient can be obtained from the estimated vehicle velocity and slip ratio. Simulations are used to validate the effectiveness of the proposed estimation method.
\end{abstract}

\section{Keywords}

estimation, method, coefficient, effective, friction, road, tyre, vehicle, study, comparative, cost, novel

Disciplines

Engineering | Science and Technology Studies

\section{Publication Details}

B. Li, H. Du \& W. Li, "Comparative study of vehicle tyre-road friction coefficient estimation with a novel cost-effective method," Vehicle System Dynamics: international journal of vehicle mechanics and mobility, vol. 52, (8) pp. 1066-1098, 2014. 


\title{
Comparative Study of Vehicle Tire-Road Friction Coefficient Estimation with a Novel Cost Effective Method
}

\author{
Boyuan $\mathrm{Li}^{1}$, Haiping $\mathrm{Du}^{1}$ and Weihua $\mathrm{Li}^{2}$ \\ 1. School of Electrical, Computer and Telecommunications Engineering, University of Wollongong, \\ Wollongong, NSW 2522, Australia \\ 2. School of Mechanical, Material and Mechatronic Engineering, University of Wollongong, \\ Wollongong, NSW 2522, Australia
}

\section{Abstract:}

This paper qualitatively and quantitatively reviews and compares three typical tire-road friction coefficient estimation methods, which are the slip slope method, individual tire force estimation method and extended Kalman filter (EKF) method, and then presents a new cost effective tire-road friction coefficient estimation method. Based on the qualitative analysis and the numerical comparisons, it is found that all the methods can successfully estimate the tire force and friction coefficient in most of the conditions, but the estimation performance is compromised for some of the estimation methods during different simulation scenarios. In addition, all of these three methods need global positioning system (GPS) to measure the absolute velocity of vehicle. To overcome the above mentioned problem, a novel cost effective estimation method is proposed in this paper. This method only requires the inputs of wheel angular velocity, traction/brake torque and longitudinal acceleration, which are all easy to be measured using available sensors installed in passenger vehicles. By using this method, the vehicle absolute velocity and slip ratio can be estimated by an improved nonlinear observer without using GPS, and the friction force and tire-road friction coefficient can be obtained from the estimated vehicle velocity and slip ratio. Simulations are used to validate the effectiveness of the proposed estimation method.

Key words: tire-road friction coefficient, estimation, slip slope method, individual tire force estimation, extended Kalman filter

\section{INTRODUCTION}

Since vehicle tires are the only part that vehicle body maintains contact with the road, information about the tire-road friction is critical to vehicle's longitudinal, lateral and roll dynamics and control. Particularly, for vehicle electronic stability control (ESC) system, if the tire-road friction coefficient can be obtained, the yaw rate can be effectively controlled to prevent vehicle skidding with the updated information about the tire-road friction coefficient [1]-[3]. For four-wheel-driving (4WD) vehicles, estimation of individual tire-road friction coefficients can help to detect which wheel needs the maximum drive torque [4]. In adaptive cruise control and collision-avoidance systems, the estimated tire-road friction coefficient can help to adjust the braking distance in real time [5]. In winter road maintenance, estimation of tire-road friction coefficient can be used to adjust de-icing materials on icy roads [6]. 
In general, the tire-road friction coefficient $\mu$ is defined as the maximum value of the normalised traction force $\rho$, which is determined by the tire longitudinal friction force, tire lateral friction force and tire vertical load as $[7,8]$ :

$$
\rho=\frac{\sqrt{F_{x}^{2}+F_{y}^{2}}}{F_{z}}
$$

where $F_{x}$ is the tire longitudinal friction force, $F_{y}$ is the tire lateral friction force and $F_{z}$ is the vertical load. Note that the tire-road friction coefficient $\mu$ only relies on the road surface type, such as ice, snow, and dry asphalt, and its value is between 0 and 1. In addition, it can be seen from (1) that the tire-road friction force is closely related to the tire-road friction coefficient. The maximum tire-road friction force that the tire can generate is determined by the tire-road friction coefficient when a particular vertical load on the tire is given.

To obtain the information about road surfaces in real time, some research proposed to use special sensors to directly measure the tire-road friction coefficient. For instance, an acoustic sensor was used to 'listen to the tire' to determine the tire-road friction coefficient $[9,10]$. An alternative method using an optical sensor was suggested to be installed at the front bumper of the car to estimate the type of road surface [11]. In addition, an optical positioning sensor was proposed to measure the displacement of the tire contact patch relative to the wheel rim to estimate the tire-road friction coefficient [12]. However, it is noted that all of these methods need expensive sensors, which are not available for conventional passenger vehicles.

Due to the difficulties in directly measuring the tire friction force or tire-road friction coefficient, in recent years some studies focused on the estimation of tire-road friction coefficient based on the vehicle model. Particularly, many research studies used the longitudinal vehicle dynamics model to analyse the tire-road friction during traction/brake motion. Three main longitudinal dynamics model based methods have been proposed so far, which are slip slope method [7, 13, 14], individual wheel friction estimation method [8, 19], and extended Kalman filter (EKF) method [15-18]. Specifically, Gustafsson [13] suggested a slip slope method based on the front wheel driving vehicle while Müller et al. [14] proposed a slip slope friction estimator only for the braking situation. Wang et al. [7] developed a slip slope method for the front wheel-, rear wheel-, and four wheel-traction or braking systems under both linear and nonlinear tire regions. Compared with Gustafsson's method and Müller's method, Wang's method greatly expanded the applicable scope for the friction coefficient identification. For the EKF method, Ray [15-17] conducted a series of studies on the vehicle state estimation and tire-road friction coefficient estimation. First, Ray developed a 9 degree-of-freedom (DOF) vehicle dynamics model and an analytic tire force model to simulate the real vehicle motion, and used a 5 DOF vehicle model to develop the EKF state estimator [15]. Then based on the developed EKF estimator in [15], the braking controller, using the estimated longitudinal slip ratio, was proposed [16]. Ray also suggested extended 
Kalman-Bucy filtering (EKBF) and Bayesian hypothesis selection method be applied to estimate the vehicle motion and friction coefficient [17]. Particularly in this study, based on the previous studies of EKF estimator in $[15,16]$, the estimated vehicle states like tire force, slip ratio and slip angle were compared statistically with a nominal analytic tire model to choose the most likely friction coefficient based on the Bayesian hypothesis selection. Note that the prior knowledge of tire parameters and tire model was not required in Ray's studies. In addition to Ray's studies, Dakhlallah et al. [18] also suggested the estimation method for vehicle state and tire-road friction coefficient based on EKF method. However, the vehicle dynamics model used by Dakhlallah et al. included a nonlinear Dugoff tire force model, which requires prior knowledge of tire parameters.

Although the above discussed estimation methods have shown different advantages, there are also some disadvantages associated with each method. To well understand these advantages and disadvantages so that novel methods can be further developed to overcome their disadvantages, this paper will qualitatively and quantitatively compare the advantages and disadvantages of three existing tire-road friction coefficient estimation methods first, and then will propose a novel estimation method based on available measurements from a passenger car to improve the estimation performance and reduce the estimation cost. Finally numerical simulations will be used to evaluate the estimation performance of the proposed estimator under different scenarios.

The remainder of this paper is organised as follows. Section II addresses the vehicle dynamics model of this research. Section III presents a brief review of three typical friction estimation methods. The qualitative and quantitative comparisons of these three methods are done in Section IV and V, respectively. The new estimation method is introduced in Section VI and the simulation validation is presented in Section VII. Finally, the conclusions are given in Section VIII.

\section{VEHICLE DYNAMICS MODEL}

In this paper, only the vehicle longitudinal motion is considered. The schematic diagram of the vehicle longitudinal motion model is shown in Figure 1. When the vehicle is under acceleration, the vehicle longitudinal dynamics model and wheel dynamics model are described as:

$$
\begin{gathered}
\dot{v}_{x w}=\frac{1}{m}\left(F_{x f}+F_{x r}\right)-C_{r} g-\frac{D_{a} v_{x}^{2}}{m}+g \sin \theta \\
\dot{\omega}_{f}=\frac{1}{I_{\omega}}\left(-F_{x f} R_{\omega}+T_{d f}\right) \\
\dot{\omega}_{r}=\frac{1}{T_{\omega}}\left(-F_{x r} R_{\omega}+T_{d r}\right)
\end{gathered}
$$


Where the wheel rolling resistance $C_{r} m g$, wind drag force $D_{a} v_{x}^{2}$ and road gradient $g \sin \theta$ are considered. $T_{d f}$ and $T_{d r}$ are the traction torques applied on front and rear wheel, respectively. $F_{x f}$ and $F_{x r}$ are front wheel and rear wheel longitudinal tire forces. $m$ denotes the vehicle mass and $v_{x}$ shows the vehicle longitudinal velocity. $\omega_{f}$ and $\omega_{r}$ are the front wheel and rear wheel angular velocities. $I_{\omega}$ denotes the wheel moment of inertia and $\boldsymbol{R}_{\omega}$ is the wheel radius. When the vehicle is in braking mode, the vehicle dynamics model is described as:

$$
\begin{gathered}
\dot{v}_{x}=\frac{1}{m}\left(F_{x f}+F_{x r}\right)-C_{r} g-\frac{D_{g} v_{x}^{\mathrm{v}}}{m}+g \sin \theta \\
\dot{\omega}_{f}=\frac{1}{I_{\omega}}\left(-F_{x f} R_{\omega}-T_{b f}\right) \\
\dot{\omega}_{r}=\frac{1}{I_{\omega}}\left(-F_{x r} R_{\omega}-T_{b r}\right)
\end{gathered}
$$

Where $T_{b f}$ and $T_{b r}$ are the braking torques applied on front and rear wheel, respectively.

The Magic Formula tire model is employed in this study to represent the nonlinear tire characteristic, which is defined as:

$F_{x f, r}=D \sin \left\{\operatorname{Carctan}\left[B s_{f, r}-E\left\{B s_{f, r}-\arctan \left(B s_{f, r}\right)\right]\right]\right\}$

Where $B, C, D, E$ are all curve fitting coefficients in the Magic Formula tire model. Particularly, $D=\mu F_{s}$, which is directly related to the vertical load $F_{z}$ and the tire-road friction coefficient $\mu$. In equation (4), the longitudinal slip ratio $s_{f, r}$ is determined by the difference between the vehicle velocity $v_{x}$ and wheel speed $R_{g} \omega_{f, r}$.

$$
\begin{gathered}
s_{f, r}=\frac{R_{\omega} \omega_{f, r}-v_{x}}{R_{i j} \omega_{f r}} \quad \text { during acceleration } \\
s_{f r}=\frac{R_{\omega} \omega_{f r}-v_{x}}{v_{x}} \quad \text { during braking }
\end{gathered}
$$

The front wheel vertical load $F_{z y}$ and rear wheel vertical load $F_{z r}$ can be derived by the following equations:

$$
\begin{aligned}
& F_{z f}=\frac{m g l_{\gamma}}{l_{f}+l_{r}} \\
& F_{z r}=\frac{m g l_{f}}{l_{f}+l_{r}}
\end{aligned}
$$


Where $l_{f}$ and $l_{r}$ are the distances from the vehicle centre of gravity (C.G.) to the front and rear axle.

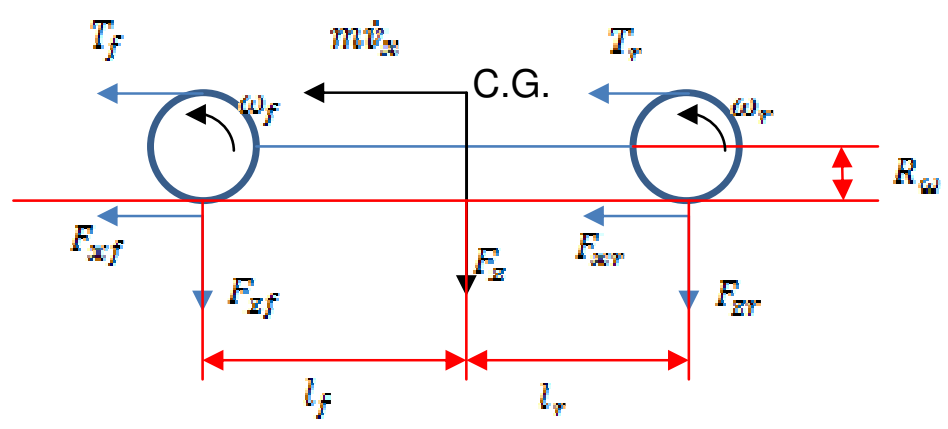

Figure 1. Schematic diagram of vehicle longitudinal motion model.

\section{REVIEW OF THREE FRICTION ESTIMATION METHODS}

\section{A. Slip Slope Method}

The slip slope method relies on the estimation of slip slope. The slip slope is defined as the initial slope of the tire longitudinal force versus slip ratio curve. The following equations about the slip slope method are mainly referred to [7].

The tire-road friction coefficient is estimated by the recursive least-squares (RLS) identification method as defined by:

$$
y(t)=\varphi(t)^{T} \theta(t)
$$

where $\theta(t)$ is the estimated slip slope, $\varphi(t)$ is the regression vector, and $y(t)$ is the vehicle total longitudinal tire force $F_{x}$, which can be obtained in terms of the measured longitudinal acceleration as:

$$
F_{x}=F_{x f}+F_{x r}=m a_{x}+C_{r} m g+D_{a} v_{x}^{2}
$$

where $\alpha_{x}$ is the longitudinal acceleration. When the tire is working in the linear region, force $F_{\mathscr{x}}$ can also be expressed as:

$$
F_{z}=F_{z f}+F_{z r}=k_{f} F_{z f} s_{f}+k_{r} F_{z r} s_{r}
$$


Assume $k_{f}=\alpha k_{r}$, then we have:

$$
F_{x}=\alpha k_{r} F_{z f} s_{f}+k_{r} F_{z r} s_{r}=k_{r}\left(\alpha F_{z f} s_{f}+F_{z r} s_{r}\right)
$$

where $\alpha$ is a coefficient used to describe the difference between the front tire stiffness and the rear tire stiffness when the vehicle is under all wheel traction or braking condition. If $\alpha=0$, the vehicle is under rear wheel driving or braking condition. According to (10), $k_{r}$ is the estimated slip slope $\theta(t)$ and $\left(\alpha F_{z f} s_{f}+F_{g r} s_{r}\right)$ is the regression vector $\varphi(t)$.

When the tire is working in the nonlinear tire region, $y(t)$ is still the vehicle longitudinal tire force $F_{x}$ but the regression vector is the vehicle vertical load $F_{x}$. The friction coefficient $\mu$ is the estimated value of $\theta(t)$. However, as there is no clear definition about when the tire begins to work in its nonlinear region, in this paper, only the estimation method in the linear condition is used for all the moving conditions.

The procedure of the RLS algorithm at each step $t$ is given as follows [7]:

> Step 1: Measure the system output $y(t)$ and calculate the regression vector $\varphi(t)$.

>SStep 2: Calculate the identification error $e(t)$, which is the difference between the system actual output at this time step and the output predicted in the previous time step:

$$
e(t)=y(t)-\varphi(t)^{T} \theta(t-1)
$$

>> Step 3: Calculate the update gain vector $K(t)$ as:

$$
K(t)=\frac{F(t-1) \varphi(t)}{\lambda+\phi(t)^{T} p(t-1) \varphi(t)}
$$

And calculate the covariance matrix $P(t)$ using:

$$
P(t)=\frac{1}{\lambda}\left[P(t-1)-\frac{P(t-1) \varphi(t) \varphi(t)^{T} P(t-1)}{\lambda+\varphi(t)^{T} P(t-1) \varphi(t)}\right]
$$

where $\lambda$ is called the forgetting factor, which is chosen between $(0.9,1)$.

>> Step 4: Update the estimated parameter:

$$
\theta(t)=\theta(t-1)+K(t) e(t)
$$


When the slip slope $k_{r}$ is estimated, the tire-road friction coefficient can be estimated by the following equation:

$$
\mu=a k_{r}+b
$$

where $a$ is the proportional constant and $b$ is the bias constant. The slip slope and the tireroad friction coefficient are constant values in ideal conditions with a particular road surface. Therefore, a linear relationship between the slip slope and the tire-road friction coefficient must exist. Based on various simulation experiments, the proportional constant $a$ and bias constant $b$ can be found. These constants will not be changed with the vehicle dynamics characteristic or tire characteristic under the same ideal conditions.

\section{B. EKF Method}

The EKF method can estimate the vehicle motion and vehicle states. Ray proposed a 9 DOF vehicle dynamics model, which included a bicycle model and a suspension model, without considering roll motion and tire model to describe the true vehicle motion [15-17]. An EKF is implemented to estimate the state according to the measured values with measurement noises.

The vehicle state estimator is defined as:

$$
\begin{gathered}
\hat{v}_{x}=\frac{1}{m}\left(\hat{F}_{x f}+\hat{F}_{x r}\right) \\
\hat{\omega}_{f}=\frac{1}{I_{\omega}}\left(-\hat{F}_{x f} R_{\omega}+T_{f}\right) \\
\hat{\omega}_{r}=\frac{1}{l_{\omega}}\left(-\hat{F}_{x r} R_{\omega}+T_{r}\right)
\end{gathered}
$$

Where $T_{f}$ and $T_{r}$ can be either the traction torque $T_{d f}\left(T_{d r}\right)$ or the brake torque $T_{b f}\left(T_{b r}\right)$. Equation (16) can be further written in the following form:

$$
\dot{x}=f(x, u)
$$

The discrete-time EKF is implemented by a forward Euler approximation as:

$x(k+1)=x(k)+T=f(x, u)$

where $T$ is the sampling time.

The system input is:

$u=\left[\begin{array}{ll}T_{f} & T_{r}\end{array}\right]$ 
The measured feedback value $z$ is same to the system output $y$ as:

$z=\left[\begin{array}{lll}a_{x} & \omega_{f} & \omega_{r}\end{array}\right]^{T}=y=h(x, u)$

The system output is set to the measured feedback value to adjust the estimation performance.

After choosing the initial value for $x_{k}^{-}$and $P_{k}^{-}$, the EKF recursive algorithm can be implemented as shown in Figure 2 [20]. The left block is the time update process and the state vector can be updated by equation (18) in discrete time domain. The right block is the measurement update process, which means that the state vector will be updated according to the error between the measured value and the estimated value.

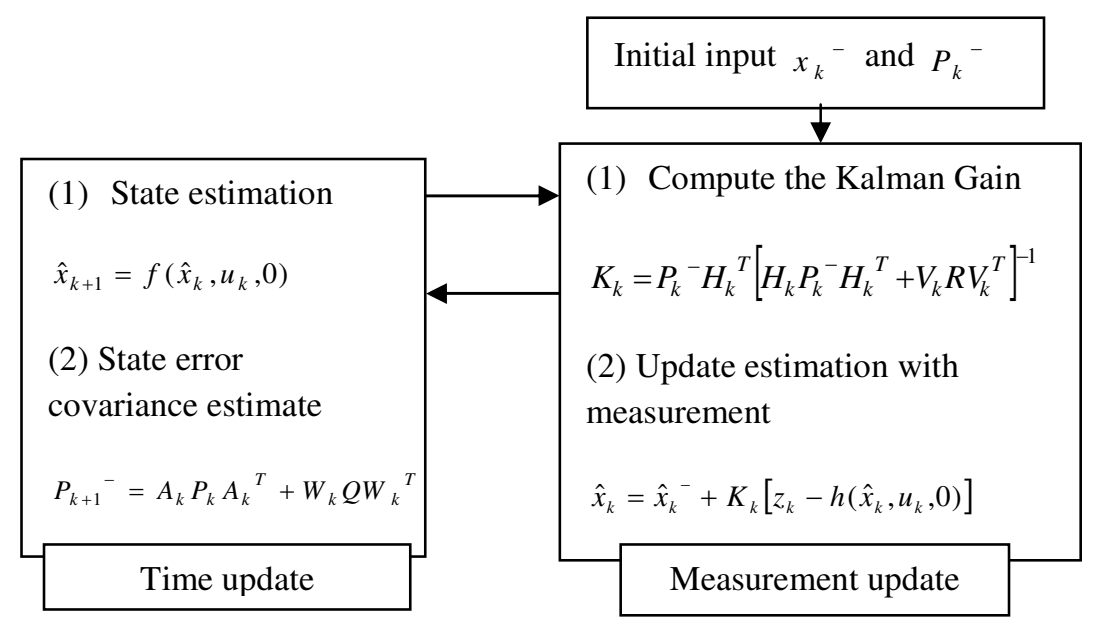

Figure 2. Working process of extended Kalman filter.

In Figure 2, $A_{k}$ and $H_{k}$ are the Jacobian matrices of partial derivative of $f(x, u)$ and $h(x, u)$ with respect to $x ; Q$ and $R$ are noise covariance matrices.

When longitudinal tire force and slip ratio is estimated by EKF method, friction coefficient can be calculated by using the RLS method.

\section{Individual Wheel Tire-Road Friction Coefficient Estimation Method}

This method can estimate the tire-road friction coefficient of each individual tire [8]. There are three steps in this estimation method:

1. Estimate the tire longitudinal friction force; 
2. Estimate the tire longitudinal slip ratio;

3. Calculate the tire-road friction coefficient by using the RLS method.

Actually, this estimation method is quite similar to Wang et al.'s slip slope method (steps 2 and 3) [7] except for the tire force estimation method (step 1). Wang et al.'s method used the accelerometer to obtain the vehicle overall longitudinal force and overall friction coefficient. However, this method uses a tire force estimator to estimate the tire force and friction coefficient of each wheel separately.

Three algorithms are proposed for this method and each of these assumes that the wheel speed measurement is available. For brevity, only two of the algorithms will be discussed in this paper for comparison purpose.

Algorithm 1: With the measurements of traction/ brake torque, wheel angular velocity, and vehicle velocity, the vehicle longitudinal tire force can be estimated by the following state space equation:

$$
\begin{gathered}
{\left[\begin{array}{c}
\hat{\sigma}_{f, r} \\
\hat{\hat{F}_{f, r}}
\end{array}\right]=\left[\begin{array}{cc}
-\frac{l}{I_{\omega}} & -\frac{R_{\omega}}{I_{\omega}} \\
\eta & 0
\end{array}\right]\left[\begin{array}{l}
\hat{\sigma}_{f, r} \\
\hat{F}_{f, r}
\end{array}\right]+\left[\begin{array}{cc}
\frac{l}{I_{\omega}} & \frac{1}{I_{\omega}} \\
-\eta & 0
\end{array}\right]\left[\begin{array}{l}
\omega_{f, r} \\
T_{f, r}
\end{array}\right]} \\
\hat{F}_{f, r}=\left[\begin{array}{ll}
0 & 1
\end{array}\right]\left[\begin{array}{c}
\omega_{f, r} \\
\hat{F}_{f, r}
\end{array}\right]+\left[\begin{array}{ll}
0 & 0
\end{array}\right]\left[\begin{array}{l}
\omega_{f, r} \\
T_{f, r}
\end{array}\right]
\end{gathered}
$$

Where $l$ and $\eta$ are positive control gain to guarantee the stable of the estimator.

The absolute longitudinal velocity of the vehicle is generally hard to measure. The GPS system is suggested here to measure the vehicle velocity, however, GPS is relatively expensive to a passenger car and it cannot be always reliable due to the change of environment such as satellite drop-outs in urban environment.

Algorithm 2: This algorithm only uses the longitudinal accelerometer and GPS-based vehicle speed measurement in the absence of traction/brake torque measurement. $v_{x}-g \sin \theta$ is the measured value of longitudinal accelerometer and the three unknown values $F_{x f^{r}} F_{x F^{m}} T_{q}$, where $T_{q}$ is the total traction/brake torque, can be estimated by the following three equations:

$$
m \dot{v}_{x}=\left(\hat{F}_{x f}+\hat{F}_{x r}\right)-C_{r} m g-D_{a} v_{x}^{2}+m g \sin \theta
$$

$$
\begin{aligned}
& I_{\omega} \dot{\omega}_{f}=c \hat{T}_{q}-R_{\omega} \hat{F}_{x f} \\
& I_{\omega} \dot{\omega}_{r}=d \hat{T}_{q}-R_{\omega} \hat{F}_{x r}
\end{aligned}
$$


Where $c$ and $d$ are the distribution ratios used to determine the fraction of total torque.

\section{QUALITATIVE COMPARISON OF DIFFERENT FRICTION ESTIMATION METHODS}

In this section, different tire-road friction estimation methods will be qualitatively compared in terms of the measurement method and advantages and disadvantages.

\section{A. Measurement Method}

The slip slope estimation method uses the GPS to measure the vehicle absolute velocity and the anti-lock brake (ABS) system to measure the wheel angular velocity. The vehicle longitudinal tire force can be estimated by the longitudinal accelerometer when the vehicle is accelerating or braking along the straight road.

The EKF method still needs the measurement of wheel angular velocity, traction/brake torque and longitudinal acceleration.

The individual wheel tire-road friction coefficient estimation method has two different estimation algorithms with different measurement requirements. In Algorithm 1, the information of traction torque and brake torque can be obtained from the CAN bus of the vehicle system and the vehicle absolute velocity can be measured by GPS. Algorithm 2 only uses the longitudinal accelerometer and GPS to estimate the tire force and measure the vehicle absolute velocity. Both of these two algorithms need the wheel angular velocity measurement from the antilock braking system.

The comparison of different measurement methods is summarised in Table I. In Table I, the wheel angular velocity, traction/brake torque and acceleration are all generally quite easy to measure (the first three columns). However, the vehicle absolute velocity (the last column) is quite hard to obtain because GPS is expensive and not reliable. Note that the proposed method in Table I is the method that will be introduced in Section VI. This method is proposed to overcome the problem of measuring the vehicle absolute velocity using GPS. Instead, this method will estimate the vehicle absolute velocity by using the available measurements of traction/brake torque, wheel angular velocity and longitudinal acceleration. More details about the principle of this novel method will be discussed in Section VI.

\section{TABLE I. COMPARISON ON MEASUREMENT METHOD OF DifFERENT FRICTION ESTIMATION} METHODS

\begin{tabular}{|l|c|c|c|c|}
\hline Estimation method & $\begin{array}{c}\text { ABS used to } \\
\text { measure wheel } \\
\text { angular velocity }\end{array}$ & $\begin{array}{c}\text { Traction/brake } \\
\text { torque } \\
\text { measurement } \\
\text { system from } \\
\text { CAN bus }\end{array}$ & $\begin{array}{c}\text { Accelerometer } \\
\text { used to } \\
\text { measure } \\
\text { vehicle } \\
\text { acceleration }\end{array}$ & $\begin{array}{c}\text { GPS based } \\
\text { vehicle speed } \\
\text { measurement }\end{array}$ \\
& & & \\
\hline
\end{tabular}




\begin{tabular}{|l|c|c|c|c|}
\hline Slip slope method & $\bigotimes$ & $\square$ & $\bigotimes$ & $\square$ \\
\hline EKF method & $\bigotimes$ & $\square$ & $\square$ & $\square$ \\
\hline Algorithm 1 & $\bigotimes$ & $\square$ & $\square$ & $\square$ \\
\hline Algorithm 2 & $\bigotimes$ & $\square$ & $\square$ & $\square$ \\
\hline Proposed method & $\bigotimes$ & $\square$ & $\square$ & $\square$ \\
\hline
\end{tabular}

\section{B. Advantages and Disadvantages of Different Estimation Methods}

The comparison on advantages and disadvantages of different estimation methods is shown in Table II.

TABLE II. COMPARISON OR ADVANTAGES AND DISADVANTAGES OF DIFFERENT FRICTION ESTIMATION METHODS

\begin{tabular}{|c|c|c|c|c|}
\hline Slip slop method & EKF method & Algorithm 1 & Algorithm 2 & Proposed Method \\
\hline $\begin{array}{l}\text { Only estimates the } \\
\text { average friction } \\
\text { coefficient. } \\
\text { Needs GPS } \\
\text { measurement } \\
\text { equipment. } \\
\text { Longitudinal tire } \\
\text { force is calculated } \\
\text { from the measured } \\
\text { acceleration without } \\
\text { the feedback value } \\
\text { to adjust the } \\
\text { measurement error } \\
\text { and bias. }\end{array}$ & $\begin{array}{l}\text { Wheel rotation } \\
\text { resistance, wind } \\
\text { drag force and } \\
\text { road gradient are } \\
\text { not considered. } \\
\text { The error will be } \\
\text { caused by the } \\
\text { linearization of } \\
\text { the nonlinear } \\
\text { vehicle dynamics } \\
\text { model in discrete } \\
\text { time. }\end{array}$ & $\begin{array}{l}\text { Needs GPS } \\
\text { measurement } \\
\text { equipment. } \\
\text { Only considers the } \\
\text { wheel dynamics and } \\
\text { does not consider } \\
\text { the vehicle } \\
\text { longitudinal } \\
\text { dynamics. }\end{array}$ & $\begin{array}{l}\text { Needs GPS } \\
\text { measurement } \\
\text { equipment. }\end{array}$ & $\begin{array}{l}\text { Does not rely on } \\
\text { the GPS } \\
\text { measurement. } \\
\text { Considers the } \\
\text { wheel dynamics } \\
\text { and vehicle } \\
\text { longitudinal } \\
\text { dynamics. } \\
\text { Considers the } \\
\text { wheel rolling } \\
\text { resistance, wind } \\
\text { drag force and } \\
\text { road gradient. }\end{array}$ \\
\hline
\end{tabular}

It can be seen from Table II that the proposed method does not rely on the GPS measurement, which is cost effective. Both the wheel dynamics and longitudinal vehicle dynamics are considered in the estimator. In addition, wheel rolling resistance, wind drag force and road gradient are included in the estimation model and the measured acceleration is utilised as the feedback value to guarantee the stability and adjust the error and bias. All of these details will be discussed in Section VI.

\section{QUANTITATIVE COMPARISON OF THREE FRICTION ESTIMATION METHODS}

In this section, numerical simulations will be used to quantitatively compare three friction estimation methods. The parameters used in the simulations are shown in Table III [21-22]. 
TABLE III. SIMULATION PARAMETERS

\begin{tabular}{|c|c|c|}
\hline$m$ & Vehicle mass & $1298.9 \mathrm{~kg}$ \\
\hline$L_{f}$ & Distance of C.G. from the front axle & $1 \mathrm{~m}$ \\
\hline$L_{r}$ & Distance of C.G. from the rear axle & $1.454 \mathrm{~m}$ \\
\hline$C_{S}$ & Longitudinal stiffness of one tire & 50000 N/unit slip \\
\hline$I_{z}$ & Vehicle moment of inertia about yaw axis & $1627 \mathrm{kgm}^{2}$ \\
\hline$R_{w}$ & Wheel radius & $0.35 \mathrm{~m}$ \\
\hline$I_{\omega}$ & Wheel moment of inertia & $2.1 \mathrm{kgm}^{2}$ \\
\hline$D_{a}$ & Wind drag coefficient & 0.4176 \\
\hline$C_{r}$ & Rolling resistance coefficient & 1.5 \\
\hline$\theta$ & Road gradient & $0.00001 \mathrm{rad}$ \\
\hline$K_{a}$ & Control gain & $\begin{array}{c}800000 \text { (140 when } \\
\text { measurement noise } \\
\text { of acceleration is } \\
\text { considered) }\end{array}$ \\
\hline$K_{\varepsilon}$ & Control gain & $\begin{array}{l}80000 \text { (140 when } \\
\text { measurement noise } \\
\text { of acceleration is } \\
\text { considered) }\end{array}$ \\
\hline$B$ & Magic formula tire parameter - stiffness factor & 20 \\
\hline$C$ & Magic formula tire parameter - shape factor & 1.5 \\
\hline$D$ & Magic formula tire parameter - peak factor & $\mu F_{z}$ \\
\hline$E$ & Magic formula tire parameter - curvature factor & -0.5 \\
\hline$a$ & Proportional constant & 0.03 \\
\hline$b$ & Bias constant & 0.1 \\
\hline
\end{tabular}

In the simulations, the vehicle initial velocity is $1 \mathrm{~m} / \mathrm{s}$. The input traction torque applied on the front and rear wheel is shown in Figure 3. The tire-road friction coefficient is set as 0.9 in the vehicle dynamics model. The rolling resistance, wind drag force and road gradient have been considered in the simulation. Note that in all the simulations of this study, process error in the simulation model is included to simulate the actual vehicle motion response, so the simulation response is not the smooth curve but is oscillating around the certain line. 
For brevity, the slip slope method is called Method 1 in the following text. The Algorithm 1 of the individual wheel tire-road friction coefficient estimation method is called Method 2 in the following text. The Algorithm 2 of the individual wheel tire-road friction coefficient estimation method is called Method 3 in the following text. The EKF based friction estimation method is also presented to compare with other estimation methods.



Figure 3. Vehicle input traction torque applied on front and rear wheel.

The comparison of the estimated tire forces is shown in Figure 4. Only the front wheel tire force is shown in the figure because the same traction or brake torque is assumed to be applied on each wheel in this study and the simulation results of the front wheel and rear wheel are similar. Note that Method 1 uses the total longitudinal tire force and the sum of front wheel slip ratio and rear wheel slip ratio to calculate the slip slope and friction coefficient according to equation (10). In the following simulations, the half value of the estimated total longitudinal force in Method 1 is compared with the estimated front wheel tire forces from other methods since the front and rear tire forces are similar. To calculate the friction coefficient, the total tire force and the sum of front and rear wheel slip ratio is used in Method 1 in the following simulations, while other methods use individual tire force and individual slip ratio to obtain the friction coefficient. It can be seen from Figure 4 that Methods 1, 2 and 3 achieve the similar tire force estimation performance. The estimated tire force of EKF method is larger than the actual measured value.

Please note that in order to show all the curves clearly, only 1 point within every 100 points of the simulation results are chosen to shown in Figure 4 to Figure 17. However, for the calculation of estimation error value in Table VI and V, all the points are used in all the figures of all the simulations. 


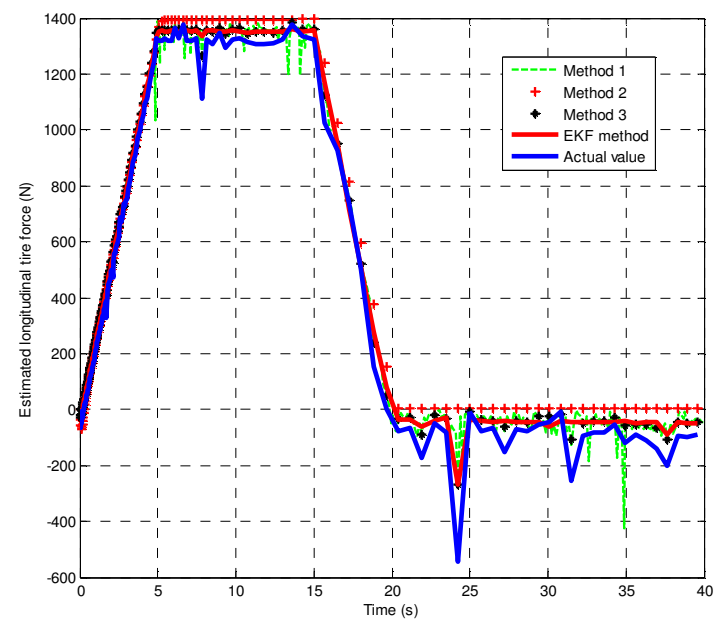

Figure 4. Comparison of the estimated front tire forces.

The comparison of the tire-road friction coefficient is shown in Figure 5. It is observed from Figure 5 that the friction coefficient has better estimation performance when the traction torque is applied for all the methods. There is no traction force applied to the vehicle body after $20 \mathrm{~s}$, but the small amount of wind drag force, rolling resistance force and road gradient still exist, which will affect the estimation performance.

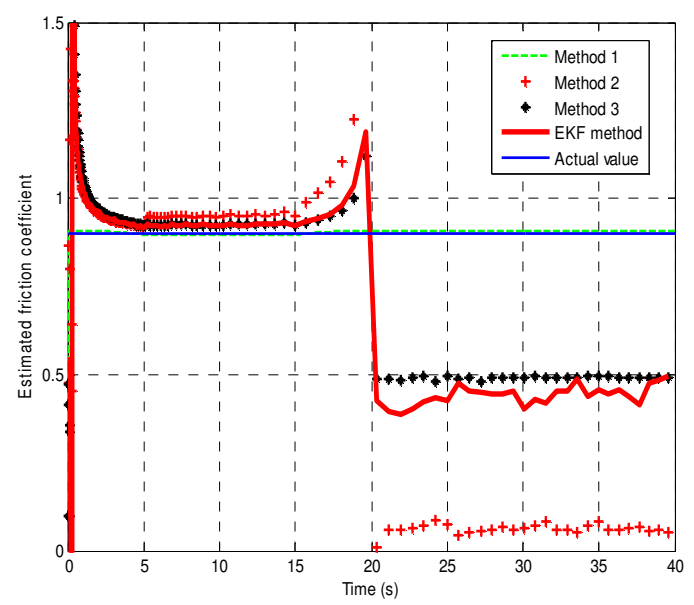

Figure 5. Comparison of the estimated front tire-road friction coefficients (actual friction coefficient is 0.9 ).

If the actual friction coefficient is changed from 0.9 to 0.5 at $10 \mathrm{~s}$ (for example the vehicle is moving from the normal road into the sand road), the estimated tire forces and friction coefficients are shown in Figures 6 and 7, respectively. 


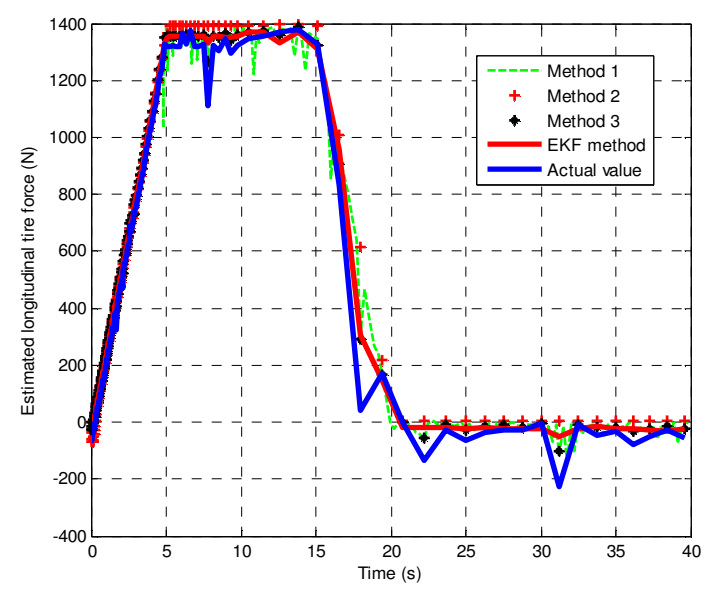

Figure 6. Comparison of the estimated front tire forces when the actual friction coefficient is changed.

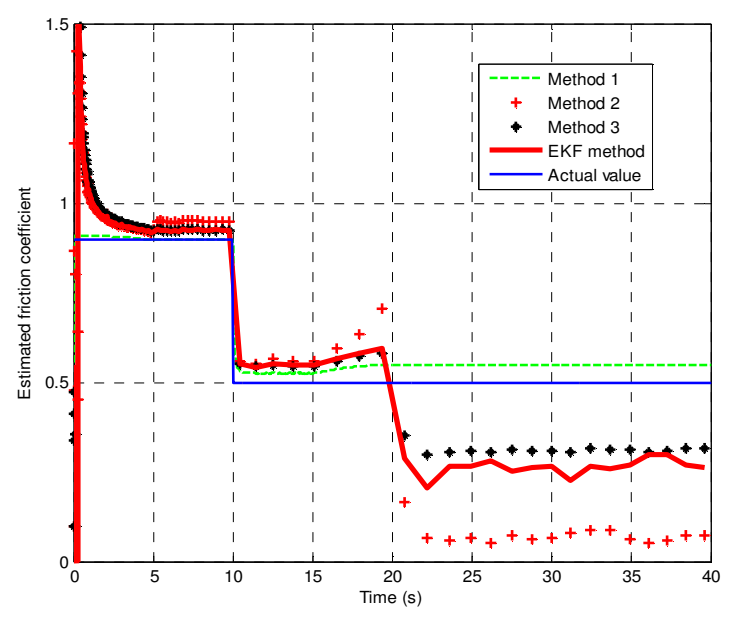

Figure 7. Comparison of the estimated front tire-road friction coefficients when the actual friction coefficient is changed.

It can be seen from Figures 6 and 7 that all the estimation methods can follow the change of road friction at $10 \mathrm{~s}$.

In reality, the longitudinal acceleration cannot be measured accurately due to the measurement noise. Figures 8 and 9 show the estimated tire forces and friction coefficients when the measurement noise of longitudinal acceleration is added (random noise with variance of 0.1 and bias offset value of 0.1 ). 


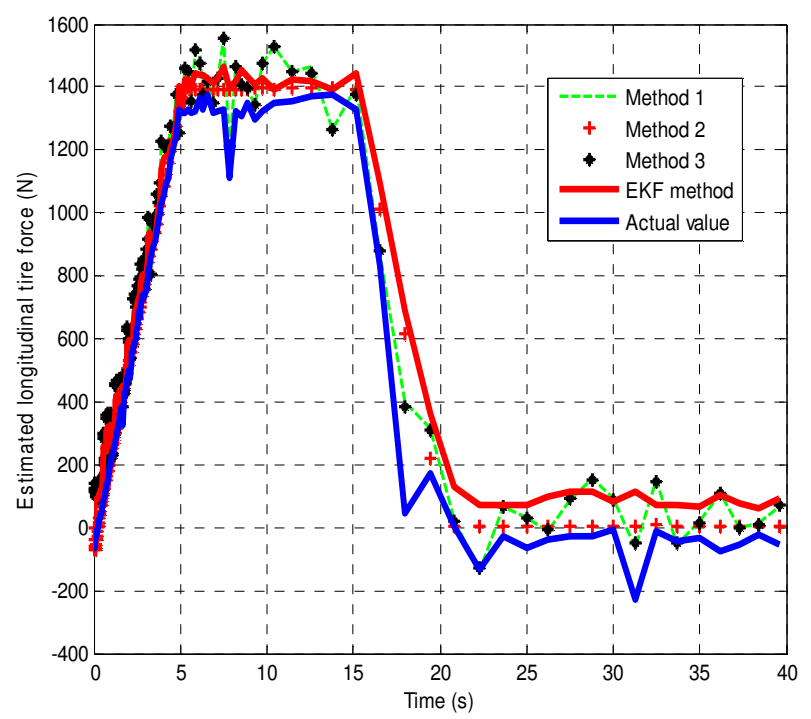

Figure 8. Comparison of the estimated front tire forces when the measurement noise of longitudinal acceleration is considered.

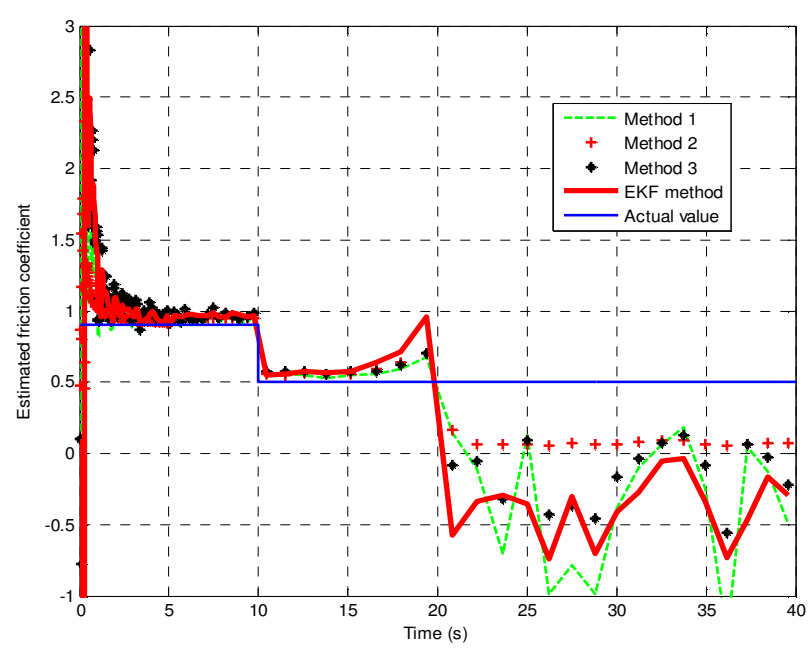

Figure 9. Comparison of the estimated tire-road friction coefficients of front tire when the measurement noise of longitudinal acceleration is considered.

From Figures 8 and 9, it is seen that the measurement noise has large impact on the estimation performance of Method 1, Method 3 and EKF method because these three methods need the input information of longitudinal acceleration, while EKF method still has better estimation performance than Method 1 and Method 3 because the measurement noise matrix in EKF can be adjusted to improve the estimation performance. Method 2 has the stable performance because the input values of Method 2 are wheel angular velocity and traction/brake torque and the longitudinal acceleration is not used.

In the above simulations, vehicle tire is working in the linear tire region due to small traction torque applied, which generates a small longitudinal slip ratio. In the following 
simulation the friction estimation performance will be evaluated when the tire is working in nonlinear tire region with large traction torque applied, as shown in Figure 10.

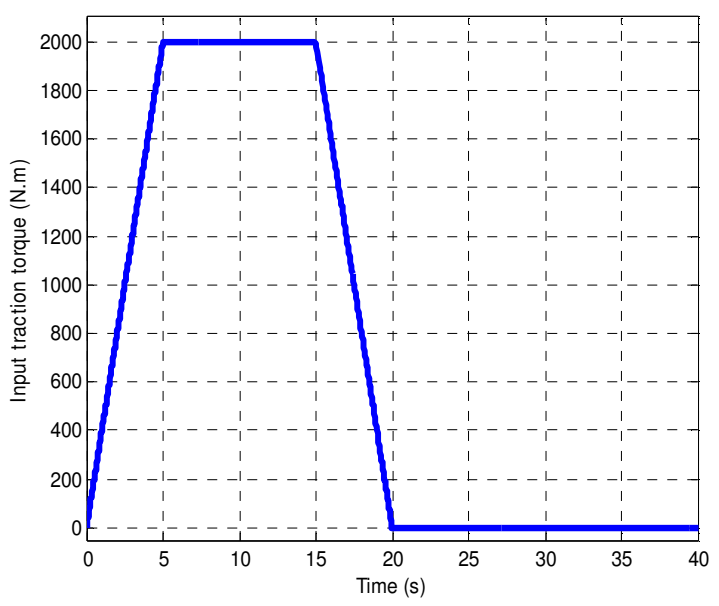

Figure 10. Large input traction torque of front and rear wheel for investigation of estimation performance in nonlinear tire region.

In this case, the comparisons of estimated longitudinal tire forces and friction coefficients are shown in Figures 11 and 12, respectively, from which it can be seen that Method 1 and EKF method cannot estimate the friction coefficient accurately due to the tire nonlinear characteristic. Method 2 and Method 3 are also affected by the tire nonlinear characteristic.



Figure 11. Comparison of the estimated front tire forces. 


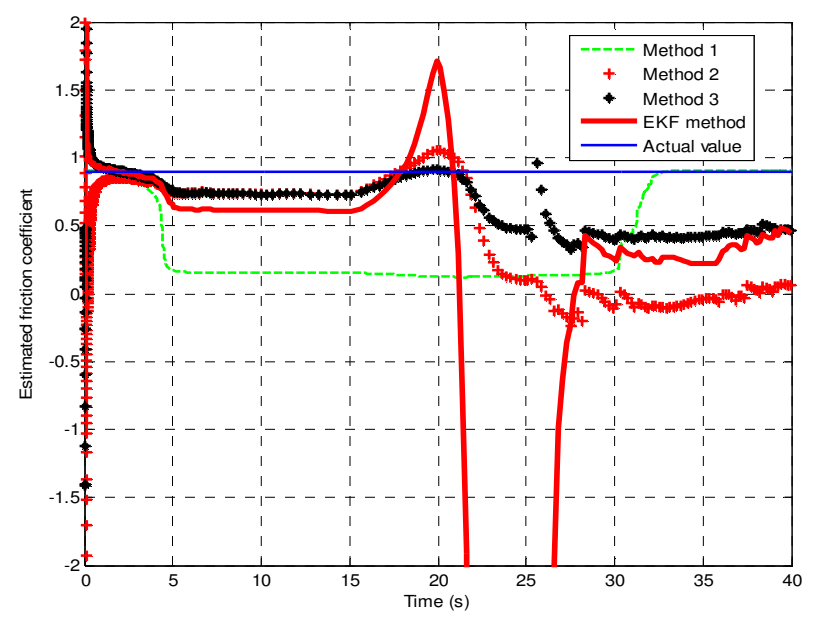

Figure 12. Comparison of the estimated tire-road friction coefficients of front tire.

Furthermore, the road gradient is changed from $0.00001 \mathrm{rad}$ to $0.01 \mathrm{rad}$ to test the robustness of these friction estimation methods. The input traction torque is same as Figure 3. In this case, the comparisons of estimated longitudinal tire forces and friction coefficients are shown in Figures 13 and 14, respectively, from which it can be seen that the simulation results of Method 1 has the best estimation performance.

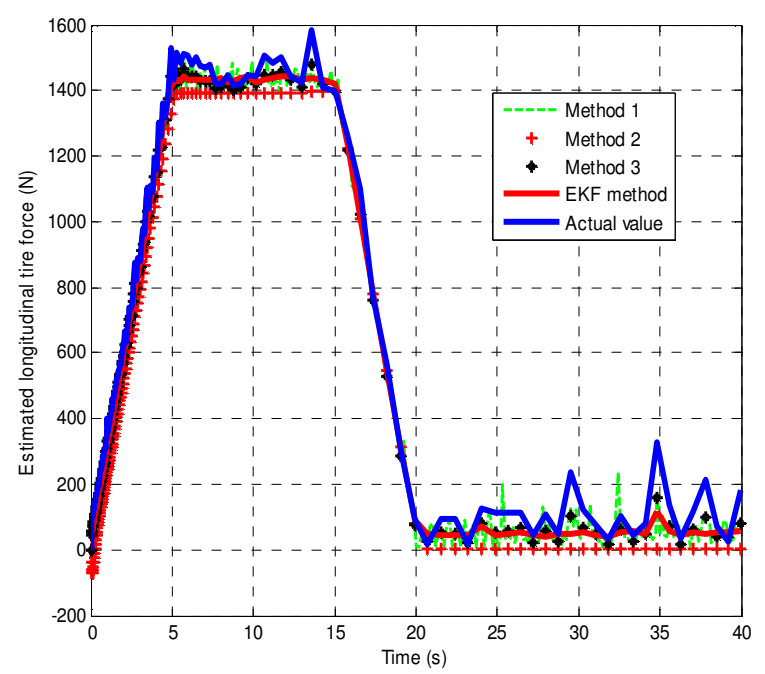

Figure 13. Comparison of the estimated front tire forces. 


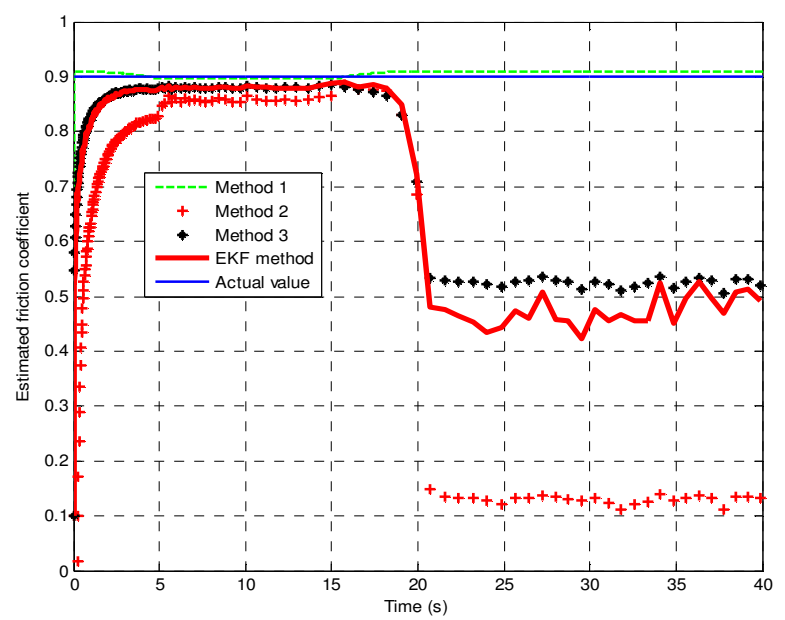

Figure 14. Comparison of the estimated tire-road friction coefficients of front tire.

Finally, vehicle traction and brake motions are simulated together to test the estimation performance of these friction estimators. The input combined traction and brake torque is shown in Figure 15. The comparisons of estimated longitudinal tire forces and friction coefficients are shown in Figures 16 and 17, respectively.

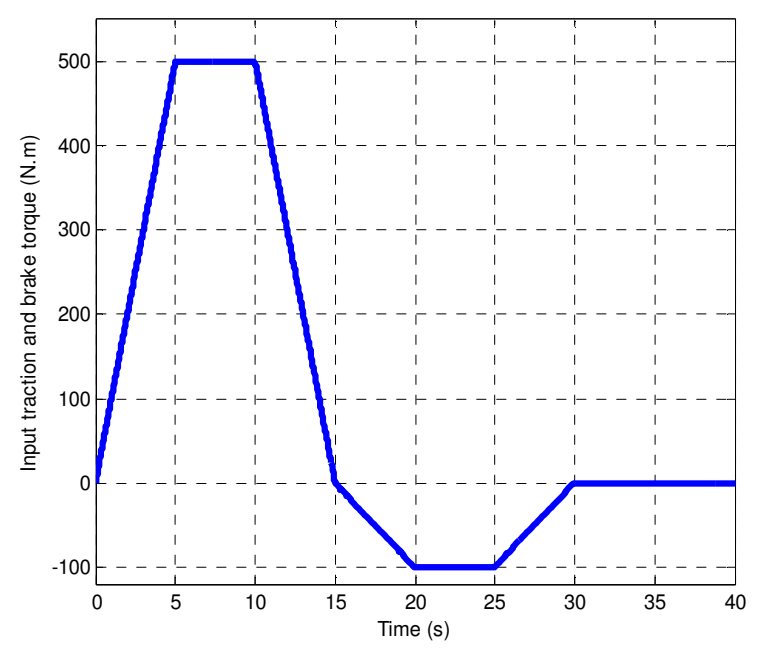

Figure 15. Vehicle input combined traction and brake torque applied on front and rear wheel. 


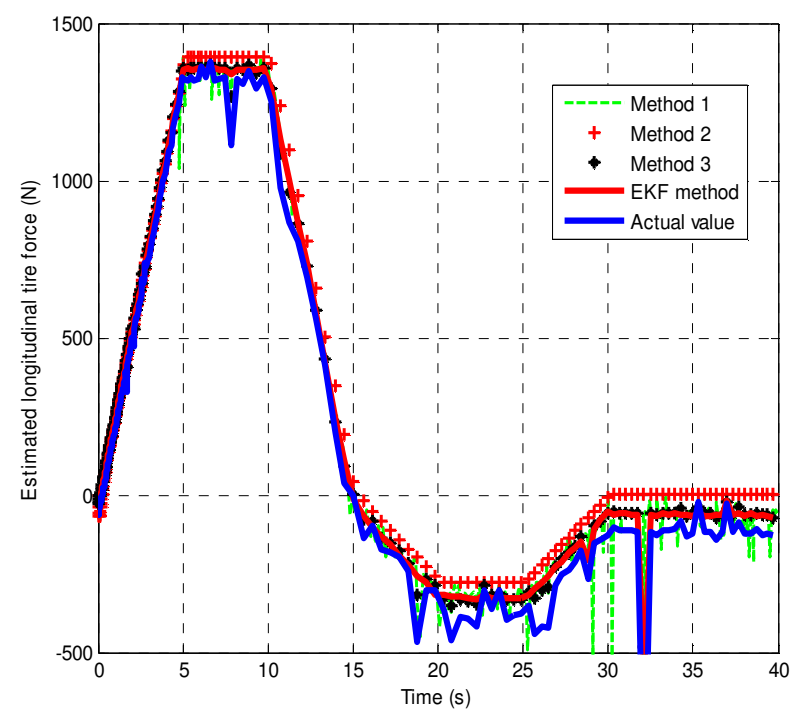

Figure 16. Comparison of the estimated front tire forces.

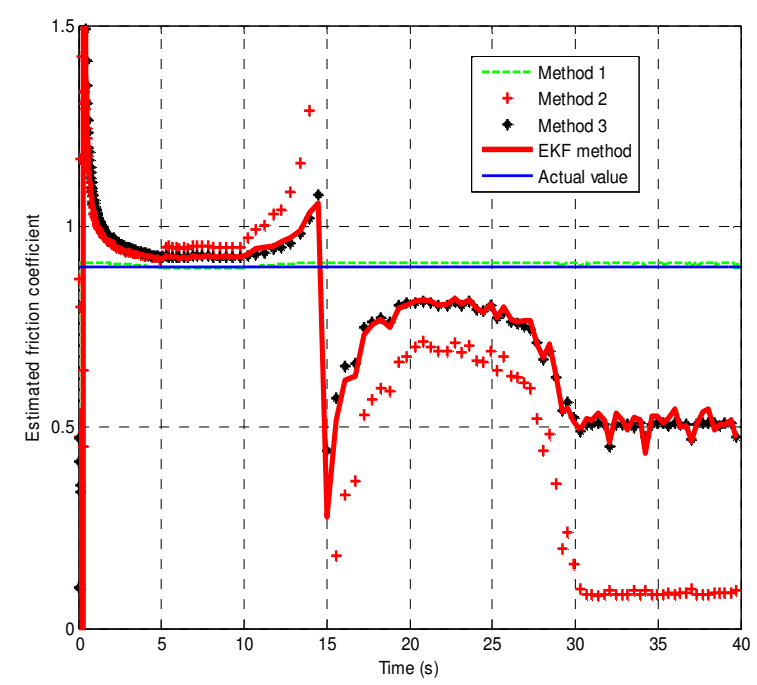

Figure 17. Comparison of the estimated tire-road friction coefficients of front tire.

It can be seen from Figures 16 and 17 that the estimation results of all the methods except Method 1 are negatively affected by the combined traction and brake motion.

In summary, all the methods can successfully estimate the tire force and friction coefficient in most of the conditions. The measurement noise of longitudinal acceleration affects the estimation performance of Method 1, Method 3 and EKF method. Method 1 has the best estimation performance during most of the simulation scenarios. However, Method 1 can only estimate the overall longitudinal tire force and friction coefficient.

In the following section, a novel tire force and friction coefficient estimator is proposed. This estimation method is cost effective because it does not need the use of expensive GPS to 
measure the vehicle absolute velocity. In addition, this method is robust and can estimate the friction coefficient in all the moving conditions successfully and more accurately.

\section{A Novel Cost EFFECTIVE TIRE-RoAd Friction COEFICIENT Estimation METHOD}

A novel cost effective tire-road friction coefficient estimation method is presented in this section. From the available ABS system, CAN bus and longitudinal accelerometer, the wheel angular speed measurement, traction/brake torque measurement and longitudinal acceleration measurement are available. Particularly for the conventional vehicle, the traction torque can be roughly calculated from engine torque by considering the reduction. The engine torque is normally obtained from measurement of engine fly-wheel speed. To improve the accuracy of measurement, high-resolution rotational motion sensors are utilised [23]. For the conventional vehicle with hydraulic braking system, the brake torque can be calculated from the measurement of oil pressure by pressure sensors in the hydraulic system [24]. These torque measurement signals are available through CAN bus. In addition, with emerging technology of in-wheel driving motor in electrical vehicle, the traction/brake torque can be easily and accurately measured and controlled from the current of driving motors [25]. A number of studies have used the input traction torque and brake torque to estimate the tireroad friction coefficient. These studies have been verified by the real experiment utilising the real vehicles, like the Volvo XC90 sport utility vehicle, with the torque measurement available on the CAN bus $[8,19,26]$. As the measurement of traction/brake torque may contain certain measurement noise, to reduce the effect of the torque measurement noise and improve the velocity estimation accuracy, a new observer is proposed with using the measured acceleration value as feedback signal and choosing appropriate feedback control gain to guarantee the convergence of the observer. The vehicle absolute velocity and slip ratio are estimated by this observer without using the expensive GPS, and the tire longitudinal force and tire-road friction coefficient of each wheel can be estimated accordingly. This method will produce a better estimation performance compared to the above discussed three methods.

There are mainly three steps in this proposed friction estimation method: (1) estimation of the longitudinal velocity and slip ratio; (2) estimation of the tire longitudinal force; and (3) estimation of friction coefficient using the results obtained from the first two steps.

\section{A. Estimation of the Vehicle Longitudinal Velocity and Slip Ratio}

First, some assumptions on the longitudinal velocity observer are made.

Assumptions: The longitudinal acceleration, traction or brake torque and wheel angular velocity are measurable. The road gradient is also known. The lateral vehicle motion is neglected. 
These assumptions are reasonable because the longitudinal acceleration can be obtained by the accelerometer and the traction or brake torque is available from the CAN bus of the vehicle system. The wheel angular velocity can be measured from the wheel speed sensor, while a longitudinal accelerometer and a vertical accelerometer can be used together to measure the road gradient [8]. As this paper is based on a vehicle longitudinal dynamics model that is applicable during vehicle acceleration and deceleration, the lateral motion is neglected.

According to the vehicle model derived in equations (2) and (3), the following equations are used for the observer design:

$$
\begin{aligned}
& \dot{v}_{x}=\frac{T_{d f}+T_{d r}-E_{\omega}\left(\dot{\omega}_{f}+\dot{\omega}_{r}\right)}{m E_{\omega}}-C_{r} g-\frac{D_{a} v_{x}^{2}}{m}+g \sin \theta \quad \text { during acceleration } \\
& \dot{v}_{x}=\frac{-\left(T_{b f}+T_{b r}\right)-I_{\omega}\left(\dot{\omega}_{f}+\dot{\omega}_{r}\right)}{m R_{\omega}}-C_{r} g-\frac{D_{a} v_{x}^{2}}{m}+g \sin \theta \quad \text { during braking }
\end{aligned}
$$

A nonlinear observer is designed to estimate the vehicle velocity as follows:

$$
\begin{aligned}
& \hat{\partial}_{x}=\left(\frac{T_{d f}+T_{d r}}{m R_{\omega}}\right) \cdot \operatorname{sat}\left(\hat{\theta}_{x}-R_{\omega} \omega_{f}\right)-\frac{I_{\omega}\left(\dot{\omega}_{f}+\dot{\omega}_{r}\right)}{m R_{\omega}}-c_{r} g-\frac{D_{a} \hat{v}_{x}^{2}}{m}+g \sin \theta \\
&+K_{a} {\left[\left(\left(\frac{T_{d f}+T_{d r}}{m R_{\omega}}\right) \operatorname{sat}\left(\hat{v}_{x}-R_{\omega} \omega_{f}\right)-\frac{I_{\omega}\left(\dot{\omega}_{f}+\dot{\omega}_{\gamma}\right)}{m R_{\omega}}-C_{r} g-\frac{D_{\alpha} \hat{v}_{x}^{2}}{m}\right)-a_{x}\right] } \\
& \quad \text { during acceleration }
\end{aligned}
$$

$$
\begin{aligned}
& \hat{\omega}_{x}=\left(\frac{T_{b f}+T_{b r}}{m R_{\omega}}\right) \cdot S a t\left(\hat{v}_{x}-R_{\omega} \omega_{f}\right)-\frac{I_{\omega}\left(\dot{\omega}_{f}+\dot{\omega}_{r}\right)}{m R_{\omega}}-c_{r} g-\frac{D_{\alpha} \hat{\theta}_{x}^{2}}{m}+g \sin \theta \\
& +K_{a}\left[\left(\left(\frac{T_{b f}+T_{b r}}{m R_{\omega}}\right) \operatorname{Sat}\left(\theta_{x}-R_{\omega} \omega_{f}\right)-\frac{T_{\omega}\left(\omega_{f}+\dot{\omega}_{\gamma}\right)}{m R_{\omega}}-C_{r} g-\frac{D_{a} \omega_{x}^{a}}{m}\right)-a_{x}\right]
\end{aligned}
$$

during braking

Where $T_{d f}, T_{d r}, T_{b f}, T_{b r}$ and $\omega_{f}, \omega_{r}$ are all the inputs of the observer, which are measurable. $a_{x}$ is the measured acceleration, which is used as the feedback value to make the observer converge with the designed feedback gain $K_{a} . \operatorname{Sat}(x)$ is a nonlinear filter function, which is defined as: 


$$
\operatorname{sat}(x)=\left\{\begin{aligned}
1, & x>d \\
-1, & x<-d \\
\frac{x}{d}, & \text { else }
\end{aligned}\right.
$$

Where $x=\hat{v}_{x}-R_{\omega} \omega_{f}$ and $d=0.1 . d$ is a small value which is used to prevent numeric oscillations between the value -1 and 1 [27].

The insight behind the nonlinear filter function (25) is that it acts like a bang-bang controller where the output $v_{x}$ will converge to the input $R_{\omega} \omega_{f}$ in steady state when there is no traction or brake torque applied. By defining the estimation error variable as $\tilde{v}_{x}=v_{x}-\hat{v}_{x}$, the error dynamics equations can be obtained by subtracting (24) from (23) as:

$$
\begin{aligned}
& \dot{v}_{x}=\left(\frac{T_{d f}+T_{a r}}{m R_{\omega}}\right)(1-\operatorname{sat}(x))-\frac{D_{a}\left(v_{x}^{2}-\hat{v}_{x}^{2}\right)}{m} \\
&-K_{a}\left[\left(\left(\frac{T_{a f}+T_{d r}}{m R_{\omega}}\right) \operatorname{sat}(x)-\frac{I_{\omega}\left(\dot{\omega}_{f}+\dot{\omega}_{r}\right)}{m R_{\omega}}-c_{r} g-\frac{D_{a} \hat{\theta}_{x}^{2}}{m}\right)-a_{w}\right]
\end{aligned}
$$

during acceleration

$$
\begin{aligned}
\hat{v}_{x}=\left(\frac{T_{b f}+T_{b r}}{m R_{\omega}}\right) & (-1-S a t(x))-\frac{D_{a}\left(v_{x}^{2}-\hat{v}_{x}^{2}\right)}{m} \\
-K_{a}\left[\left(\left(\frac{T_{b f}+T_{b r}}{m R_{\omega}}\right) \operatorname{Sat}(x)-\frac{I_{\omega}\left(\dot{\omega}_{f}+\omega_{r}\right)}{m R_{\omega}}-c_{r} g-\frac{D_{a} \hat{\sigma}_{x}^{2}}{m}\right)-a_{x}\right] & \quad \text { during braking }
\end{aligned}
$$

As the measured acceleration is $a_{x}=\frac{T_{d j f}+T_{d r}-T_{\omega}\left(\dot{\omega}_{z}+\dot{\omega}_{r}\right)}{m R_{\omega}}-C_{r} g-\frac{D_{a} v_{x}^{2}}{m}$ (while acceleration) and $a_{x}=\frac{-\left(T_{b f}+T_{b r}\right)-T_{u}\left(\dot{\omega}_{f}+\dot{\omega}_{r}\right)}{m R_{\omega}}-C_{r} g-\frac{D_{z} v_{x}^{2}}{m}$ (while braking), thus, the error dynamics equation of the observer can be re-arranged as follows:

$$
\begin{gathered}
\hat{v}_{x}=-\left(\frac{T_{d f}+T_{d r}}{m R_{\omega}}\right)(\operatorname{Sat}(x)-1)-\left(1+K_{a}\right) \frac{D_{a}\left(v_{x}+\hat{v}_{x}\right)}{m} \tilde{v}_{x} \\
-K_{a}\left[\left(\frac{T_{d f}+T_{d r}}{m R_{\omega}}\right)(\operatorname{Sat}(x)-1)\right] \tilde{v}_{x}
\end{gathered}
$$

$$
\begin{gathered}
\hat{v}_{x}=-\left(\frac{T_{b f}+T_{b r}}{m R_{\omega}}\right)(\operatorname{Sat}(x)+1)-\left(1+K_{a}\right) \frac{D_{a}\left(v_{x}+\hat{v}_{x}\right)}{m} \tilde{v}_{x} \\
-K_{a}\left[\left(\frac{T_{b f}+T_{b r}}{m R_{\omega}}\right)(\operatorname{Sat}(x)+1)\right] \tilde{v}_{x}
\end{gathered}
$$


Hence, with the condition that $K_{a}>0$, we have $t \rightarrow \infty, \tilde{v}_{x} \rightarrow 0, \operatorname{Sat}(x) \rightarrow 1$ when acceleration and $\operatorname{Sat}(x) \rightarrow-1$ when braking and $\tilde{v}_{x} \rightarrow 0$. Therefore, the observer can ensure stable estimation of vehicle velocity. The structure of the propose observer is shown in Figure 18.



Figure 18. Structure of the proposed vehicle velocity observer.

After the longitudinal velocity is estimated, the vehicle longitudinal slip ratio is obtained from the measured wheel angular speed and estimated longitudinal velocity by equation (5). 


\section{B. Estimation of the Vehicle Longitudinal Force}

In this subsection, the vehicle longitudinal tire force will be estimated instead of using expensive sensors to measure it. The vehicle acceleration can be utilised as the measurement information to update the error gain and improve the estimation accuracy. Therefore, this estimation method is cost effective and reliable. In addition, this estimator can estimate the front and rear tire force individually.

Assumptions: Vehicle longitudinal slip ratio is available from the results of above section and longitudinal acceleration is measurable. Tire lateral force is neglected.

According to equation (5), the tire longitudinal slip ratio can be determined if the vehicle velocity can be accurately estimated. Then the front longitudinal tire force and rear longitudinal tire force can be estimated in equation (28).

$$
\begin{gathered}
F_{x f}=k s_{f} \\
F_{x r}=k \frac{F_{z r}}{F_{z f}} s_{r}
\end{gathered}
$$

where $k$ is the ratio between the tire force and tire slip ratio. To improve the estimation accuracy, this ratio will be updated in real time according to the error between the measured acceleration and the total estimated longitudinal tire force. This is given by:

$$
e=\left(\hat{F}_{x f}+\hat{F}_{x r}\right)-\left(m a_{x}+C_{r} m g+D_{a} v_{x}^{2}-m g \sin \theta\right)
$$

The block diagram of the tire force estimator is shown in Figure 19. It can be seen that $k$ indicates the longitudinal stiffness of the tire and will be updated according to the measured acceleration. In this way, the relationship between the estimated tire force and slip ratio is no longer a simple linear relationship with a constant value but a nonlinear relationship. $K_{g}$ is the control gain which is used to adjust the value of $k$ according to the error $e . C_{z}$ is the tire longitudinal stiffness in the linear tire region, which is a constant value.




Figure 19. Block diagram of the improved individual tire force estimator.

\section{Estimation of Friction Coefficient}

The slip slope $k_{r}$ is determined according to the RLS algorithm given in Section III. When the slip slope $k_{r}$ is estimated, based on the experimental data in the simulation, the tire-road friction coefficient can be estimated by equation (15).

\section{Remark:}

Considering the possible measurement noise on acceleration. In practice, a low-pass signal filter [7] is used to accommodate the measurement noise for acceleration. The estimation performance of the proposed friction estimator is improved in the simulation when the filter is applied, which will be shown in Table VI and VII in next section.

\section{VALIDATION OF ThE PROPOSED NOVEL FRICTION ESTIMATION METHOD}

To validate the effectiveness of the proposed method, numerical simulations similar to Section V will be conducted. The parameters used in the simulations are same as the parameters given in Table I.

In the first test, the traction torque is applied as same as Figure 3 and the initial velocity is also $1 \mathrm{~m} / \mathrm{s}$. The actual friction coefficient is set as 0.9 in the vehicle dynamics model similar to Section V.

Figure 20 compares the actual vehicle velocity with the estimated vehicle velocity, which proves that the improved nonlinear observer given in equation (24) can effectively estimate the vehicle absolute velocity.

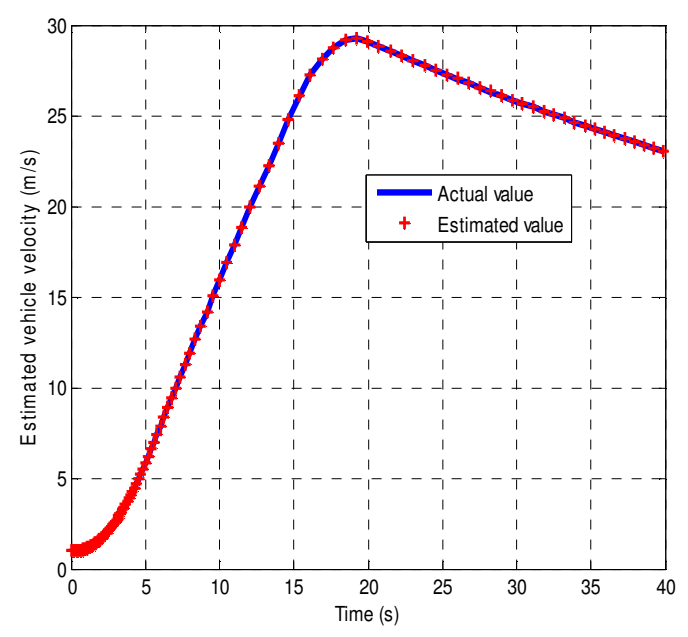

Figure 20. Comparison of the estimated vehicle absolute velocity. 
Figure 21 shows the tire force estimation of the proposed estimator compared to the actual tire force. This result proves that the force estimation result of the proposed estimator is acceptable. Similar to Section V, only front tire force and friction coefficient are shown in this section.

Note that in the following figures, all the points in the simulation are presented to clearly show the simulation results.

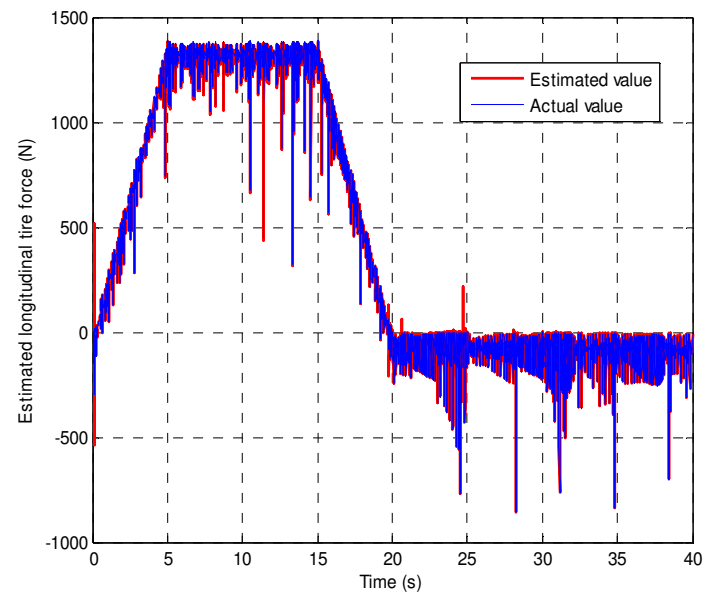

Figure 21. Comparison of the estimated front tire longitudinal forces.

The estimation of friction coefficient is shown in Figure 22. Compared with Figure 5, it can be seen that the proposed estimator shows better estimation performance.



Figure 22. Comparison of the estimated tire-road friction coefficients of front tire.

If the actual friction coefficient is changed from 0.9 to 0.5 at $10 \mathrm{~s}$ (for example, the vehicle is moving from the normal road into the sand road), the estimated tire forces and friction coefficients are shown in Figures 23 and 24, respectively. 


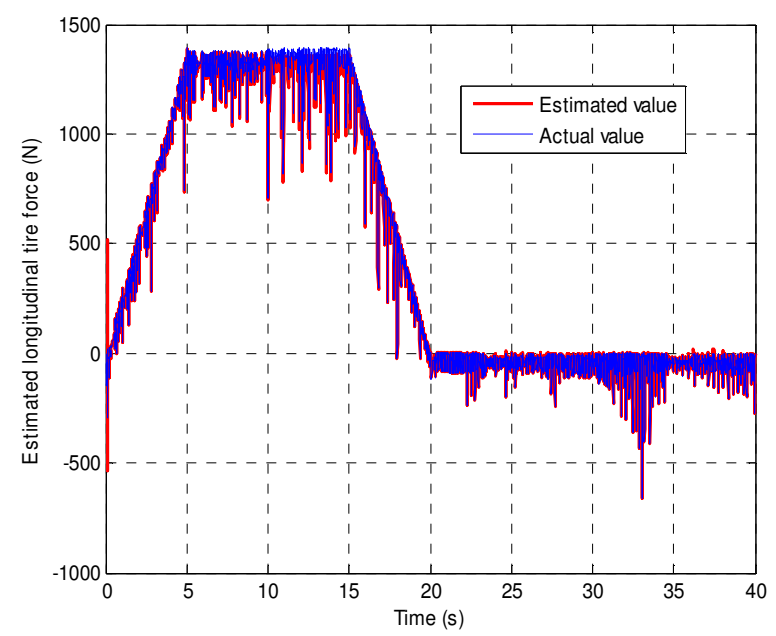

Figure 23. Comparison of the estimated front tire forces when the actual tire-road friction coefficient is changed.

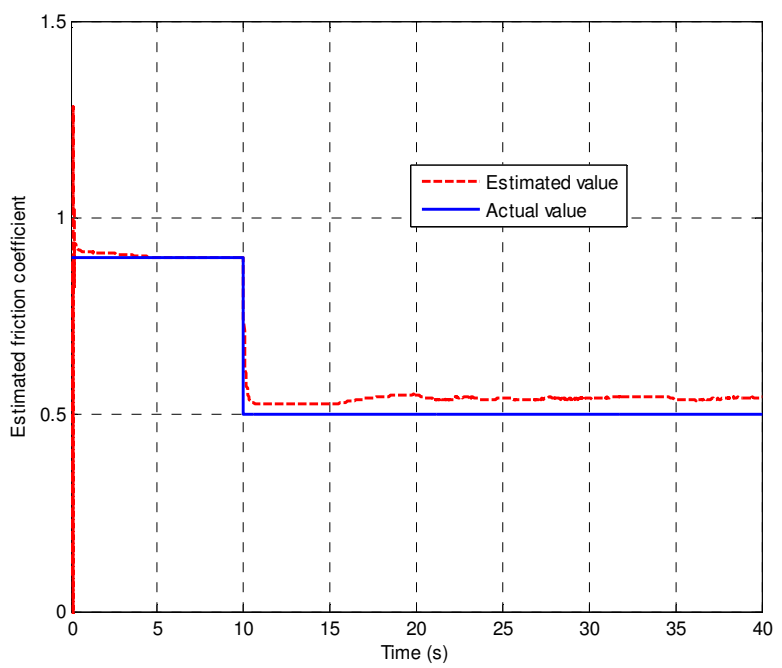

Figure 24. Comparison of the estimated front tire friction coefficients when the actual tireroad friction coefficient is changed.

Comparing Figure 24 with Figure 7, it can be seen that the newly proposed estimation method achieves better performance on the estimation of the friction coefficient. Note that these figures also suggest that the estimation performance is compromised when the friction coefficient is changed from 0.9 to 0.5 during 10 to 15 seconds compared with Figure 22 . However, this disadvantage can be neglected during the whole time range of vehicle motion and the RMS error shown in Table VI and Table VII is not significantly affected by this disadvantage.

If the measurement noise of longitudinal acceleration is considered, the estimated tire forces and friction coefficients are shown in Figures 25 and 26, respectively. 


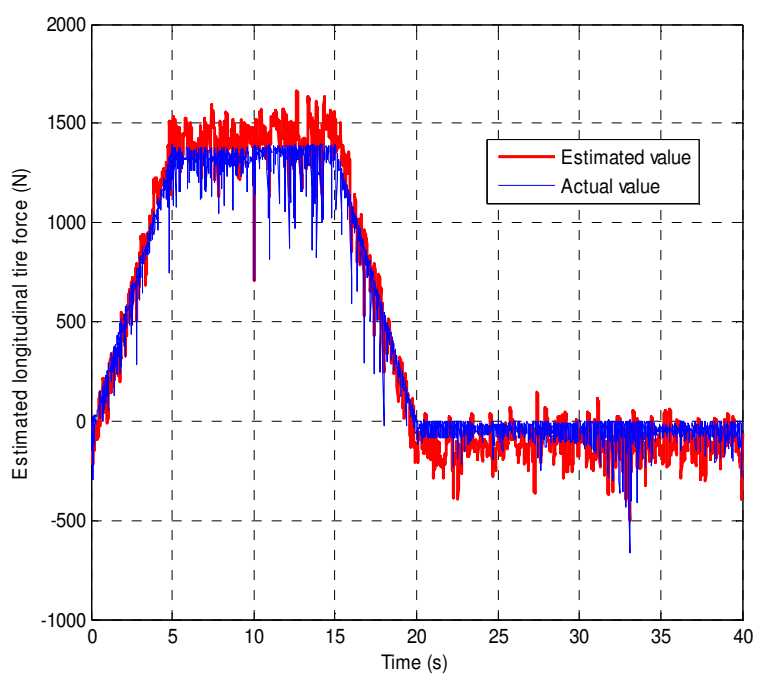

Figure 25. Comparison of the estimated front tire forces when the measurement noise of longitudinal acceleration is considered



Figure 26. Comparison of the estimated tire-road friction coefficients of front tire when the measurement noise of longitudinal acceleration is considered.

Comparing Figure 25 with Figure 8, when the longitudinal acceleration measurement is not reliable, the proposed method can still improve the estimation performance of tire force by decreasing the feedback control gain about the acceleration and relying more on the torque measurement. For the friction coefficient estimation, the estimation performance can be improved by directly using the GPS to measure the vehicle velocity to obtain the slip ratio since the using of acceleration measurement to estimate the velocity is not reliable.

If the large traction torque is applied (same as Figure 10) so the vehicle is operating in the nonlinear tire region, the estimated tire forces and friction coefficients are shown in Figures 27 and 28 , respectively. 


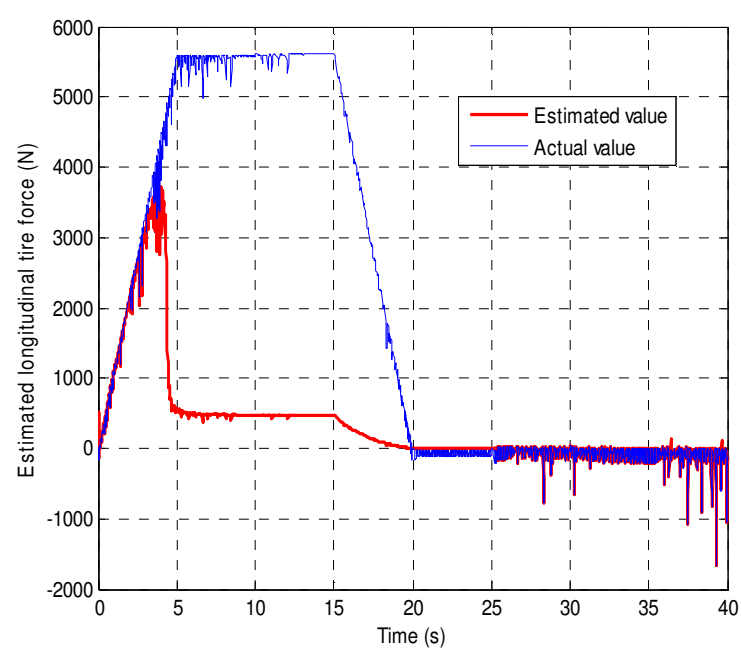

Figure 27. Comparison of the estimated front tire forces when the large input traction torque is applied.



Figure 28. Comparison of the estimated tire-road friction coefficients of front tire when the large input traction torque is applied.

According to Figures 27 and 28, the estimated tire force and friction coefficient are not accurate when the large traction torque is applied because the tire is working in the nonlinear tire region. Although the proposed estimator can update the longitudinal stiffness, the estimator is still based on the linear relationship between the tire force and slip ratio, which cannot accurately represent the nonlinear relationship between them. Figure 27 suggests that the estimator can accurately estimate the front tire force when it is not larger than about 3800 $\mathrm{N}$. However, this novel estimator can find the accurate friction coefficient immediately when the tire begins to work in the linear region after $25 \mathrm{~s}$.

In addition, road gradient can also be changed (from 0.00001 to 0.01 ) to test the robustness of estimation performance of the proposed estimator. According to Figure 29 and Figure 30, the proposed estimation method has good estimation performance even when the road gradient is increased. 




Figure 29. Comparison of the estimated front tire forces when the road gradient is considered.

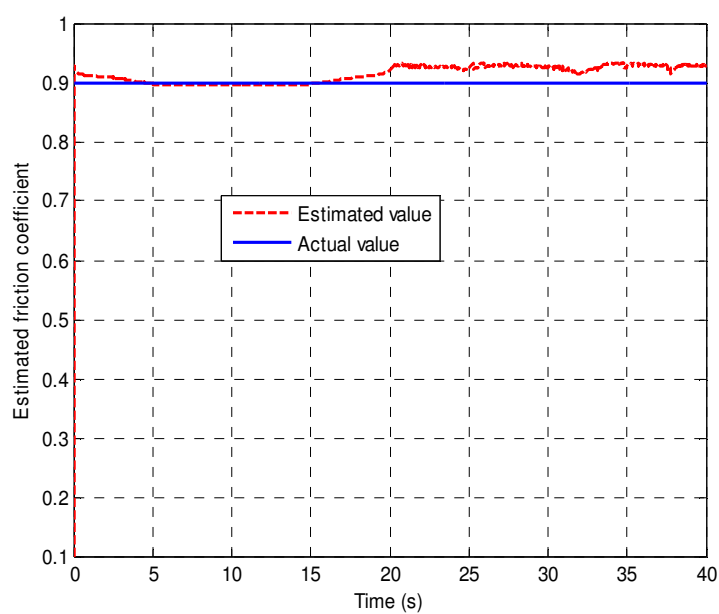

Figure 30. Comparison of the estimated front tire-road friction coefficients when the road gradient is considered.

Finally, the combined traction and brake motion is applied to evaluate the estimation performance of estimator. Figure 31 and Figure 32 also suggest that the proposed estimator has better performance than other methods. 




Figure 31. Comparison of the estimated front tire forces when considering the combined traction and brake motion.

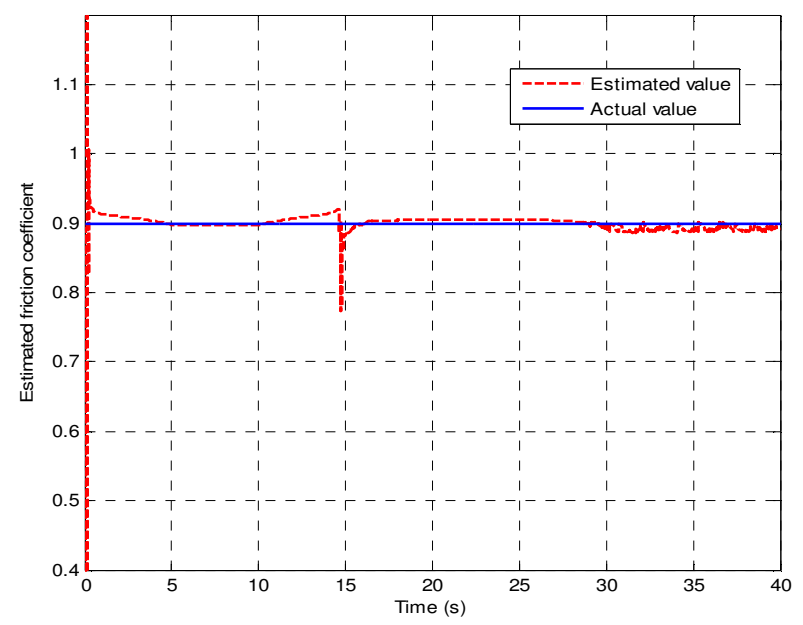

Figure 32. Comparison of the estimated front tire-road friction coefficients when considering the combined traction and brake motion.

To compare the results more clearly, the root mean square (RMS) value of estimation error of the proposed method is compared with other existing methods as discussed in Section V. The comparison results are shown in Table IV and Table V for the front tire force and the tireroad friction coefficient, respectively. 
TABLE IV. RMS of estimation error of front tire force (unit: $\mathrm{N}$ )

\begin{tabular}{|l|c|c|c|c|c|}
\hline Scenarios Method 1 & Method 2 & Method 3 & EKF method & $\begin{array}{c}\text { Proposed } \\
\text { method }\end{array}$ \\
\hline $\begin{array}{l}\text { Simple turning } \\
\text { condition }\end{array}$ & 44.67 & 76.58 & 45.44 & 48.05 & 8.738 \\
\hline $\begin{array}{l}\text { Changed friction } \\
\text { coefficient }\end{array}$ & 38.84 & 57.88 & 39.54 & 40.58 & 10.56 \\
\hline $\begin{array}{l}\text { Considering the } \\
\text { measurement } \\
\text { noise } \\
\text { acceleration of }\end{array}$ & 124.68 & 58.94 & 124.72 & 112.58 & 92.70 \\
\hline $\begin{array}{l}\text { Large traction } \\
\text { torque }\end{array}$ & 439.75 & 127.62 & 55.43 & 440.15 & 1305 \\
\hline $\begin{array}{l}\text { Considering the } \\
\text { road gradient }\end{array}$ & 42.88 & 117.3 & 44.15 & 53.09 & 3.283 \\
\hline $\begin{array}{l}\text { Combined } \\
\text { traction and brake } \\
\text { motion }\end{array}$ & 55.11 & 103.7 & 57.33 & 58.28 & 7.5838 \\
\hline
\end{tabular}

TABLE V. RMS of estimation error of front tire-road friction coefficient

\begin{tabular}{|l|c|c|c|c|c|}
\hline Scenarios & Method 1 & Method 2 & Method 3 & EKF method & $\begin{array}{c}\text { Proposed } \\
\text { method }\end{array}$ \\
\hline $\begin{array}{l}\text { Simple turning } \\
\text { condition }\end{array}$ & 0.0186 & 0.4229 & 0.8465 & 0.7045 & 0.0421 \\
\hline $\begin{array}{l}\text { Changed friction } \\
\text { coefficient }\end{array}$ & 0.0280 & 0.2774 & 0.8871 & 0.7269 & 0.0481 \\
\hline $\begin{array}{l}\text { Considering the } \\
\text { measurement } \\
\text { noise } \\
\text { acceleration of } \\
\text { signal }\end{array}$ & 2.033 & 0.2774 & 2.703 & 1.247 & 1.905 \\
\hline $\begin{array}{l}\text { Large traction } \\
\text { torque }\end{array}$ & 0.3000 & 0.7005 & 0.3624 & 2.126 & 0.2635 \\
\hline $\begin{array}{l}\text { Considering the } \\
\text { road gradient }\end{array}$ & 0.0195 & 0.4842 & 0.1817 & 0.2083 & 0.0233 \\
\hline $\begin{array}{l}\text { Combined } \\
\text { traction and brake } \\
\text { motion }\end{array}$ & 0.0175 & 0.4220 & 0.7832 & 0.6482 & 0.0388 \\
\hline
\end{tabular}

It is confirmed from the simulation results that the novel friction coefficient estimation method shows good performance in the normal, in the friction coefficient variation, in the road gradient changing and in the combined traction and braking condition simulations when compared with other existing methods. When the measurement noise is considered, the proposed method still has the acceptable performance. However, this estimation method cannot work well when the tire is working in the extreme nonlinear tire region. Table IV and Table $\mathrm{V}$ also show that the estimation performance is improved when the filter described at the end of Section VI is applied at the scenario of considering the measurement noise of acceleration signal. Compared with Method 1, the proposed method has better estimation results of tire force and the worse estimation results of friction coefficient. This is because 
than Method 1 uses the direct measurement velocity from GPS to calculate the slip ratio, while the proposed method uses the estimation of velocity to calculate the slip ratio. The estimate velocity can compromise the estimation results of slip ratio and friction coefficient.

\section{CONCLUSIONS}

This study compares three existing friction coefficient estimation methods qualitatively and quantitatively, and the advantages and disadvantages of these methods are identified. According to qualitatively comparisons, the slip slope method can only estimate the vehicle average friction coefficient. The individual tire force estimation method requires expensive GPS equipment to determine the velocity. The EKF method uses linearized discrete time vehicle dynamics model for estimation which has error for the nonlinear vehicle dynamics system. Simulations for the quantitative comparisons show that all the methods can successfully estimate the tire force and friction coefficient in most of the conditions. The measurement noise of longitudinal acceleration affects the estimation performance of all these methods except Method 2. Method 1 has the best estimation performance during most of the simulation scenarios. However, Method 1 can only estimate the overall longitudinal tire force and friction coefficient.

In this paper, a novel cost effective tire-road friction coefficient estimation method is proposed. This method only needs to measure the wheel angular velocity, the traction/brake torque and the longitudinal acceleration, which are all easy to be measured using available sensors installed in passenger vehicles. The vehicle absolute velocity can be estimated by the nonlinear observer without using the expensive GPS. Simulations are used to validate the effectiveness of the proposed method. From the simulation results, it is confirmed that the proposed method shows good performance in the normal, in the friction coefficient variation, in the road gradient changing and in the combined traction and braking condition simulations when compared with other existing methods. When the measurement noise is considered, the proposed method still has the acceptable performance. However, this estimation method cannot work well when the tire is working in the extreme nonlinear tire region. In the future, real experiments will be conducted to verify the proposed estimation method.

\section{Acknowledgements}

The authors would like to thank the anonymous reviewers for their invaluable comments and suggestions, which are helpful for improving the quality of the paper. Thanks are also given to Dr Paul Walker, University of Technology, Sydney, Australia, for reading through the paper and providing very good suggestions. 


\section{REFERENCES}

[1] H. E. Tseng, D. Madau, B. Ashrafi, T. Brown, and D. Recker, "Technical challenges in the development of vehicle stability control system", in Proc. IEEE Int.Conf.Control Applications, HI, Aug.1999, pp.1660-1666.

[2] A. T. van Zanten, "Bosch ESP systems: 5 years of experience," In Proc. SAE Automotive Dynamics and Stability Conf., Troy. MI, May 2000, Paper No. 2000-01-1633.

[3] A. Nishio, K. Tozu, H. Yamaguchi, K. Asano, and Y. Amano, "Development of vehicle stability control system based on vehicle sideslip angle estimation," SAE Paper, No. 2001-01-0137.

[4] L. Austin and D. Morrey, "Recent advances in antilock braking systems and traction control systems," Proc.Inst.Mech.Eng.D, vol.214, no.6, pp.625-638, 2000.

[5] K. Yi and J. Taeyoung, "Observer based estimation of tire-road friction for collision warning algorithm adaptation,” JSME Int.J.Series C. vol.41, no.1, pp.116-124, Mar.1998.

[6] G. Erdogan, L.Alexander, and R.Rajamani, "Friction coefficient measurement system for autonomous winter road maintenance", Vehicle System Dynamics, vol.47, no.4, pp.497-512, 2009.

[7] J. Wang, L. Alexander, and R. Rajamani, "Friction estimation on high-way vehicles using longitudinal measurements", ASME J. Dyn. Syst.,Meas. Control, vol.126, no.2, pp.265-275, 2004.

[8] R. Rajamani, G. Phanomchoeng, D. Piyabongkarn, and J. Y. Lew, "Algorithms for Real-Time Estimation of Individual Wheel Tire-Road Friction Coefficients", IEEE/ASME Transactions on Mechatronics, vol.17, no.6, 2012, pp.1183-1195.

[9] B. Breuer, U. Eichhorn, and J. Roth, "Measurement of Tyre-Road Friction Ahead of the Car and inside the Tyre", in Proc. Int. Symp. Advanced Vehicle Control, 1992, pp. 347-353.

[10] U. Eichhorn and J. Roth, "Prediction and Monitoring of Tyre-Road Friction", in Proc. FISITA, London, 1992, pp.67-74.

[11] T. Uno, Y. Sakai, J. Takagi, and T. Yamashita, "Road Surface Recognition Method Using Optical Spatial filtering", in Proc. AVEC, 1994, pp.509-515.

[12] "Intelligent Tyre for Accident-Free Traffic", Apollo Consortium, APOLLO Final Report, IST-2001-34372, Finland, July 2005.

[13] F. Gustaffson, 1997, "Slip-Based Tire-Road Friction Estimation," Automatica, vol.33, no.6, pp.1087-1099.

[14] S. Müller, M. Uchanski, and H. Karl, "Slip-Based Tire-Road Friction Estimation During Braking," Proceedings of 2001 ASME International Mechanical Engineering Congress and Exposition, New York, pp.213-220, 2001.

[15] L. R. Ray, "Nonlinear estimation of vehicles state and tire forces", American Control Conference, Chicago, pp.526-530, 1992.

[16] L. R. Ray, "Nonlinear state and tire force estimation for advanced vehicle control", IEEE Transactions on Control Systems Technology, vol.3, no.1, pp.117-124, 1995. 
[17] L. R. Ray, "Nonlinear tire force estimation and road friction identification: Simulation and experiments," Automatica, vol.33, pp. 1819-1833, 1997.

[18] J. Dakhlallah, S. Glaser, S. Mammar, and Y. Sebsadji, "Tire-Road Forces Estimation Using Extended Kalman Filter and Side slip Angle Evaluation”, 2008 American Control Conference, USA, pp.4597-4602, 2008.

[19] R. Rajamani, D. Piyabongkarn, J.Y. Lew, and J.A. Grogg, "Algorithms for Real-Time Estimation of Individual Wheel Tire-Road Friction Coefficient", Proceedings of the 2006 American Control Conference, Minnesota, June 14-16, 2006, pp.4682-4687.

[20] G. Welch, and G. Bishop, “An Introduction to the Kalman Filter", September 17, 1997.

[21] B. Boada, M. Boada, and V. Díaz, "Fuzzy-logic Applied to Yaw Moment Control for Vehicle Stability”, Vehicle System Dynamics, 43, pp.753-770, 2005.

[22] T. Lam, H. Qian, and Y. Xu, "Omnidirectional Steering Interface and Control for a Four-Wheel Independent Steering Vehicle”, IEEE/ASME Transactions on Mechatronics, 15, pp.329-338, 2010.

[23] N.Cavina, F. Ponti, and G. Rizzoni, "Fast algorithm for on-board torque estimation," in SAE Int. Congr. Expo., Detroit, MI, Mar. 1, 1999, Paper 1999-01-0541.

[24] T. Svensson, I. Moore, and R. Daniels, "Method for operating a hydraulic brake system of a motor vehicle and a hydraulic braking system", US Patent, app.13/733,041, 2013.

[25] G. Xu, K. Xu, and W. Li, "Novel estimation of tyre-road friction coefficient and slip ratio using electrical parameters of traction motor for electric vehicles", Int. J. Vehicle Autonomous Systems, vol. 11, nos. 2/3, pp.261-278, 2013.

[26] R. Rajamani, D. Piyabongkarn, J. Y. Lew, K. Yi, and G. Phanomchoeng, 'Tire-Road Friction-Coefficient Estimation', IEEE Control System Magazine, August 2010, pp.54-69.

[27] F. Jiang, and Z. Gao, "An Adaptive Nonlinear Filter Approach to the Vehicle Velocity Estimation for ABS", Proceedings of the 2000 IEEE International Conference on Control Applications, USA, pp.490-495, 2000. 